\title{
A EDUCAÇÃO NA ERA DA ECONOMIA DO CONHECIMENTO
}

Descontinuidades tecnológicas vêm produzindo, ao longo da história, mudanças estruturais profundas no modelo de sociedade. Foi assim no final do século XVIII com a máquina a vapor, dando início a revolução industrial. Outro momento importante se deu com a descoberta da eletricidade, quando as indústrias automobilísticas começaram a produzir carros em série. Nos meados do século XX veio a descoberta do transistor, e um novo modelo de sociedade começou a prosperar, a então chamada sociedade da informação.

Nos tempos mais recentes as mudanças estruturais são cada vez mais frequentes, em que alguns chamam da Era da Economia do Conhecimento. E o mundo do trabalho, por conseqüência, tem sido cada vez mais impactado pela dinâmica dessas descontinuidades tecnológicas. Um estudo do Departamento do Trabalho dos Estados Unidos mostrou, por exemplo, que as dez profissões que mais empregaram em 2009 nem sequer existiam em 2004. Preparar jovens para essa nova Era torna-se assim um grande desafio para instituições e organizações.

Outro estudo realizado pela Organização para Cooperação e Desenvolvimento Econômicos (OCDE) revelou que quando a formação dos indivíduos permite que competências e habilidades sejam desenvolvidas e aperfeiçoadas ao longo de suas vidas, eles demonstram maior capacidade de responder a essas descontinuidades tecnológicas.

Apesar dessa compreensão, a maioria dos países ainda vive o drama de não ser capaz de oferecer uma escola e um professor para um aluno do século 21. Uma das consequências, desse desalinhamento, são os baixos níveis de aprendizagem apresentados pelos seus estudantes em avaliações internacionais, como o PISA (Programa Internacional de Avaliação de Alunos, do inglês Programme for International Student Assessment). O Brasil, por exemplo, está entre os países com menor desempenho.

Nas avaliações nacionais, o País mostra avanços expressivos nas séries iniciais do Ensino Fundamental. Por outro lado, não vem conseguindo avançar nas séries finais dessa etapa da Educação Básica e principalmente, no Ensino Médio. Prover uma Escola de qualidade para nossa juventude, a chamada
1. e-mail: mozart@ todospelaeducacao. org.br 
Escola do Jovem,éainda um desafio educacional a ser vencido. $\mathrm{O}$ jovem quer uma escola que caiba na vida, e hoje, em geral, ele não encontra em nosso país.

O gargalo do Ensino Médio não é de agora, já vem de longe. Faltam professores e um currículo atraente para uma escola de tempo integral, que possa se articular com o Ensino Técnico-profissionalizante. Com isso o Brasil vai perdendo mais uma geração de jovens num momento em que sua economia começa a dar sinais de estagnação, após um período de grande crescimento.

Outra conseqüência do gargalo do Ensino Médio, é que o país passa por uma janela demográfica, o chamado bônus demográfico. $\mathrm{Ou}$ formamos bem os nossos jovens ou não teremos quem sustente a nossa economia num futuro próximo. Faltará, o que já vem sendo observando em vários setores, mão de obra qualificada para atender as demandas. O Brasil terá que importar jovens. Segundo projeções do IPEA (Instituto de Pesquisa Econômica Aplicada), a partir de 2030, daqui a 17 anos, os únicos grupos populacionais que deverão crescer são os que têm mais de 45 anos. Será nesse mesmo ano que a população atingirá seu ponto máximo chegando a 208 milhões.

Um país que quer ser protagonista num cenário mundial competitivo, não pode se acomodar com uma geração "nem-nem"-jovens que nem trabalham e nem estudam. Segundo estudo do Senai, o país tem hoje 5,3 milhões de brasileiros, entre 18 e 29 anos, que estão excluídos do mercado de trabalho e do ensino formal.

Para resolver o problema da mão de obra qualificada e de jovens bem preparados para esse novo cenário, as empresas e o sistema " $\mathrm{S}$ " começam a investir fortemente no aumento da escolaridade de seus trabalhadores, tal como vem fazendo a Federação das Indústrias de Santa Catarina (FIESC), que acaba de lançar o movimento A Indústria pela Educação. Essa iniciativa prevê o aumento de escolaridade e a qualificação profissional para mais de $800 \mathrm{mil}$ trabalhadores até 2014, assegurando postos de trabalho e qualidade de vida. O engajamento das empresas nesse movimento poderá inspirar outros movimentos similares. A própria Confederação Nacional da Indústria (CNI) acaba de lançar a Educação para o Mundo Trabalho. Ogoverno brasileiro também começa a acordar para este desafio ao colocar em prática o Pronatec (Programa Nacional de acesso ao Ensino Técnico e Emprego); para 2014, estão previstas 800 mil matrículas envolvendo o Senai e as instituições de ensino superior. Uma coisa é certa, o Brasil só entrará, de fato, no século XXI quando for capaz de prover uma Educação de qualidade para todos os brasileiros. E não há mais tempo a perder! 

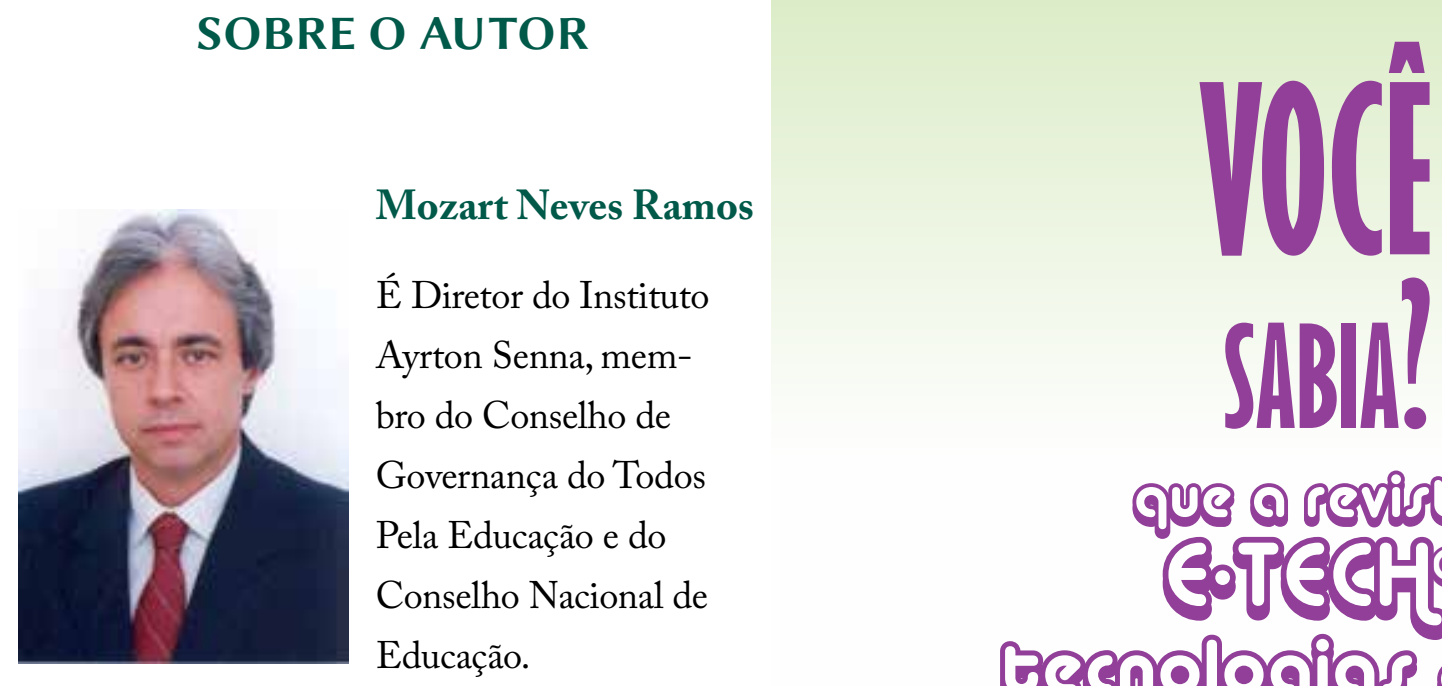

QUS Q rovtbiso

3oTBCH?

vesnologitas stingtw

$\circ$ aiven $133^{3}$

no slasstlleasåo do

PUPLIP ERPESP

***

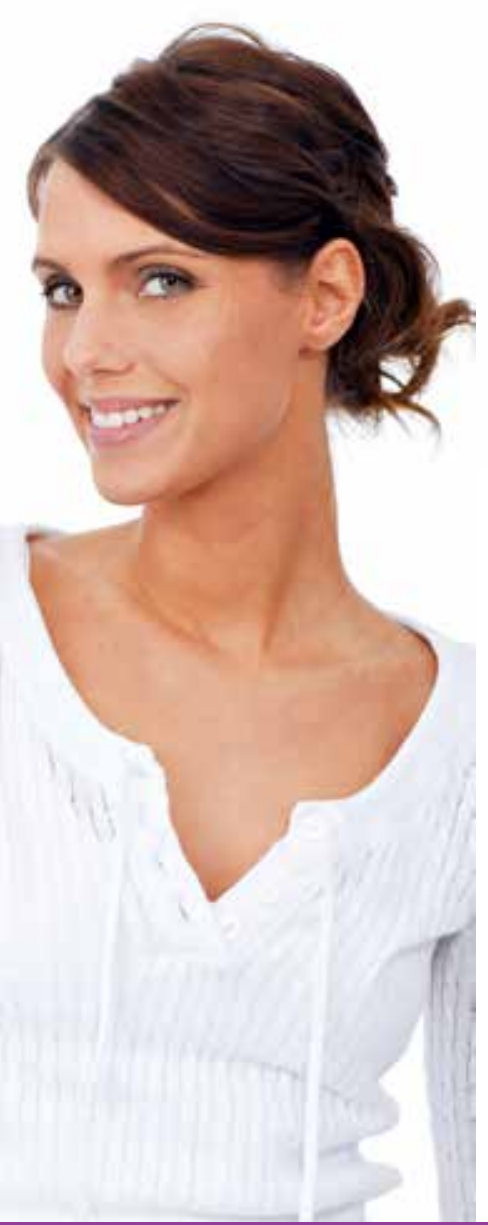

* PONTUAÇÃo Do QUALIS NO PERíOdo 2013/2014. VEJA AS

DEMAIS PONTUAÇÕES EM WWW.SC.SENAI.BR/E-TECH.

ReVista E-TECH. Mais tecnologia para

A COMPETITIVIDADE DA INDÚSTRIA. 